\title{
Electrical Optical and Structural Properties of p-type Silicon
}

\author{
Mehnaz Sharmin $^{1 *}$, Shamima Choudhury ${ }^{2}$ and Tahmina Begum ${ }^{3}$ \\ ${ }^{I}$ Department of Physics, Bangladesh University of Engineering and Technology, \\ Dhaka-1000, Bangladesh \\ ${ }^{2}$ Department of Physics, Dhaka University, Dhaka-1000, Bangladesh \\ ${ }^{3}$ Experimental Physics Division, Atomic Energy Center, Dhaka-1000, Bangladesh
}

(Received: 16 April 2014; Accepted: 03 June 2014)

\begin{abstract}
Electrical, optical and structural properties of p-type single crystal silicon were investigated in this work. Electrical conductivity of p-type silicon was measured in the temperature ranges $190-300 \mathrm{~K}$. The acceptor ionization energy ( $\left.\mathrm{E}_{\mathrm{A}}\right)$ was between $0.047-0.051 \mathrm{eV}$. Photoconductivity of the material was investigated by varying sample current, light intensity and temperature at a constant chopping frequency of $45.60 \mathrm{~Hz}$. Absorption co-efficient ( ) of the material was calculated from optical transmittance and reflectance measurements at room temperature $(300 \mathrm{~K}$ ) in the wavelength range of $300-2500 \mathrm{~nm}$. The direct optical band gap energy was found between $2.10-2.20$ $\mathrm{eV}$ and the indirect optical band gap energy was found between $0.95-1.0 \mathrm{eV}$. The lattice parameter (a) was found to be $5.419 \AA$ from $\mathrm{X}$-ray diffraction method (XRD).
\end{abstract}

Keywords: Electrical conductivity, Photoconductivity, Absorption co-efficient, Optical band gap.

\section{Introduction}

Silicon (Si) is a well known intrinsic semiconductor which shows various interesting electrical and optical properties when doped with impurity (such as B, Al, P, As etc.). p-type $\mathrm{Si}$ has wide applications in the field of solar cells, light emitting diodes, photo detectors, lasers, transistors, specialized IC's etc. Electrical properties of single crystal silicon containing arsenic (As) and boron (B) were studied ${ }^{1}$ and the boron acceptor level was found to be $0.045 \mathrm{eV}$ for low impurity concentration. Infrared absorption measure-ments have shown the existence of shallower acceptor levels associated with both boron and gallium in silicon and the optical ionization energies of boron and silicon were obtained $^{2}$ as $37.1 \pm 0.3$ and $57.0 \pm 0.3 \mathrm{meV}$ respectively. Deep Level Transient Spectroscopy (DLTS) and Energy Resolved Tunneling Photoconductivity (ERTP) spectroscopy measurements were studied ${ }^{3}$ at cryogenic temperatures on silicon, where electrically active defects were induced by ion implantation of boron and phosphorus into silicon. Intrinsic optical absorption in single crystal germanium (Ge) and Si was studied ${ }^{4}$ at the temperatures 77 and $300 \mathrm{~K}$, the threshold for direct transition was found to be at $2.5 \mathrm{eV}$ and that for indirect transitions were at $1.06 \mathrm{eV}$ and $1.16 \mathrm{eV}$ at 300 and $77 \mathrm{~K}$, respectively. Microwave Photoconductive decay $(\mu-\mathrm{PCD})$ was used $^{5}$ to find out the copper $(\mathrm{Cu})$ contamination in p-type $\mathrm{Si}$ and it was found that the method was capable of measuring $\mathrm{Cu}$ concentrations down to $10^{10}$ $/ \mathrm{cm}^{3}$. The optical parameters and the thickness of Si: $\mathrm{H}$ thin films were determined ${ }^{6}$ from transmission spectrum in the range of 400-2500 $\mathrm{nm}$ using the envelope method and detailed analysis was carried out to obtain the optical band gap $\left(\mathrm{E}_{\mathrm{g}}\right)$ using Tauc's method and the estimated values were $1.99 \mathrm{eV}, 2.01 \mathrm{eV}$ and $1.75 \mathrm{eV}$. Optical properties such as dark conductivity and photoconductivity were investigated ${ }^{7}$ on nano crystalline silicon dark conductivity activation energy was found as $0.43 \mathrm{eV}$ and optical band gap was in the range $2.3-2.5 \mathrm{eV}$. The photovoltaic effect in silicon solar cells were investigated ${ }^{8}$ by using a near-field scanning microwave microscope (NSMM) technique and it was found that photoconductivity in the solar cells varied due to the incident light intensities and the wavelength. Optical properties such as absorption co-efficient, reflectivity, band gap of intrinsic silicon was studied ${ }^{9}$ at $300 \mathrm{~K}$ between the wavelength range 400-1100nm. XRD, Raman Spectroscopy, TEM and SEM of the silicon films were carried out ${ }^{10}$ and the optical band gap was found to be varying from 2.19 to $2.63 \mathrm{eV}$.

In this work, electrical conductivity ( ) of p-type single crystal Si was studied by the variation of temperature between 190 to $300 \mathrm{~K}$ to determine the acceptor ionization energy. The effects of variation of sample current, light intensity and temperature on photoconductivity of the p-type $\mathrm{Si}$ were studied at constant chopping frequency of $45.60 \mathrm{~Hz}$. Absorption co-efficient ( ) and optical band gap of p-type Si was obtained from the measurements of optical transmittance and reflectance with a UV-vis-NIR spectrometer of photon wavelength range $300-2500 \mathrm{~nm}$. Similar works have been reported $\mathrm{d}^{11,12}$ on gallium arsenide (GaAs). The aim of present work was to observe the nature of electrical conductivity of ptype Si below room temperature, photoconductive response, the nature of optical absorption, inter-band transition and estimating optical band gap energy.

\section{Methods}

Rectangular shaped pieces of different dimensions were cut by a diamond cutter Buehler $^{\mathbb{Q}}$, ISOMET ${ }^{\mathrm{TM}}$, Low Speed Saw, USA) from a round shaped p-type single crystal $\mathrm{Si}$ wafer (purchased from wafer technology, UK) of $3.5 \mathrm{~cm}$ in diameter. The mechanically damaged surfaces of the samples were polished with 100 grit $\mathrm{SiC}$ powder and 1.0 micron alpha alumina powder respectively in polisher (Buehler Ecomet III Grinder, U.S.A). The samples were then cleaned with acetone and de-ionized water in an ultrasonic bath (Kerry, USA) ${ }^{13}$. Electrical leads were soldered to the end faces of the samples by Indium. The electrical resistivity of the p-type $\mathrm{Si}$ wafers was measured by both four point probe at room temperature and that of the rectangular shaped samples was measured by two point probe method by varying the temperature from $190 \mathrm{~K}-300$ $\mathrm{K}$. To decrease the temperature of the samples a liquid

"Author for correspondence.e-mail: proggaph@gmail.com 
Nitrogen cryostat was used. A Copper-Constantan thermocouple was attached to the sample holder and the temperature was measured by a digital temperature controller (cyber). The cooling rate was maintained at $0.00533 \mathrm{~K} / \mathrm{sec}^{14}$.

Modulated illumination ${ }^{15}$ method was used for measuring photoconductivity. Chopping frequency was measured by a light chopper (125/99, EG \& G, PARC). The DSP lock-inamplifier (7225, Signal Recovery) was used for photoconductivity measurements. To increase the temperature of the sample above room temperature a nicrome heater $(35 \mathrm{~W})$ and power supply (Philips) were used. The temperature was measured using Copper-Constantan thermocouple and digital temperature controller. Heating rate was maintained at $0.00533 \mathrm{~K} / \mathrm{sec}$. Light source used was $100 \mathrm{~W}$ quartz halogen lamp. Intensity of light was measured by a lux meter (LX 101). Optical transmittance ( $\mathrm{T}$ $\%)$ and reflectance $(\mathrm{R} \%)$ of p-type $\mathrm{Si}$ samples were investigated using a UV-3100 (dual beam) recording spectrophotometer in the wavelengths ( ) range 300$2500 \mathrm{~nm}$ and absorption co-efficient ( ) was calculated from those data.

Lattice parameter of the p-type Si was determined by X-ray diffraction (XRD) method using a Philips PW 3040 X' Pert PRO XRD system with $\mathrm{Cu}-\mathrm{K}$ radiation, operated at $40 \mathrm{kV}$ and $30 \mathrm{~mA}$, with angular range $20^{\circ} \leq 2 \leq 80^{\circ}$.

\section{Results and Discussion}

Resistivity of the p-type Si wafers were measured at $300 \mathrm{~K}$ temperature by four point probe method, the values obtained were 2.26 and $1.18-\mathrm{cm}$, respectively. The resistivity of $\mathrm{p}$ type $\mathrm{Si}$ was also measured at $300 \mathrm{~K}$ temperature by two point probe method and the values were 2.38, 3.94 and 2.91

-cm, respectively. The current-voltage (I-V) characteristics curves of the samples are shown in Fig. 1. Since the I-V plots are linear, it can be concluded that the contacts were ohmic.

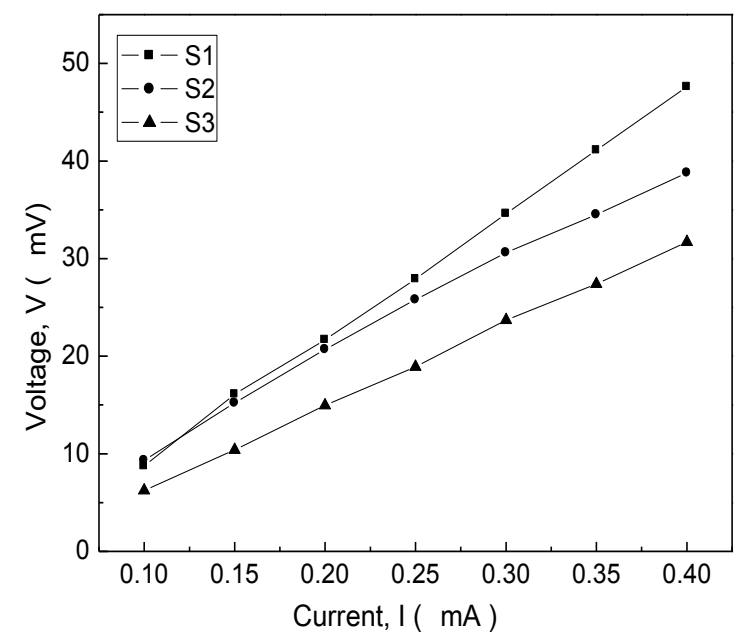

Fig. 1. Voltage (V) versus Current (I) graphs of p-type silicon.
Temperature dependence of electrical conductivity of an intrinsic semiconductor can be written as an exponential function of $\mathrm{T}$ as follows ${ }^{16}$,

$$
\mathrm{i}(\mathrm{T})=A \mathrm{e}^{-\frac{\mathrm{Eg}}{2 \mathrm{kT}}}
$$

Equation (1) may be converted into equation (2).

$\ln { }_{i}(T)=\ln A-\frac{E_{g}}{2 k T}$

A plot of $\ln _{i}$ versus $1 / T$ appears almost linear with a negative slope. The fobbiden energy gap $\left(E_{g}\right)$ and acceptor ionization energy $\left(E_{A}\right)$ of a semiconductor impurity level can be determined from the slope of the straight line at higher and lower temperature regions, respectively ${ }^{16}$.

The temperature dependence of electrical conductivity (Fig.2) indicates exponential increase with temperature ${ }^{16}$. This may be because of the generation of free charge carrier due to thermal excitation.

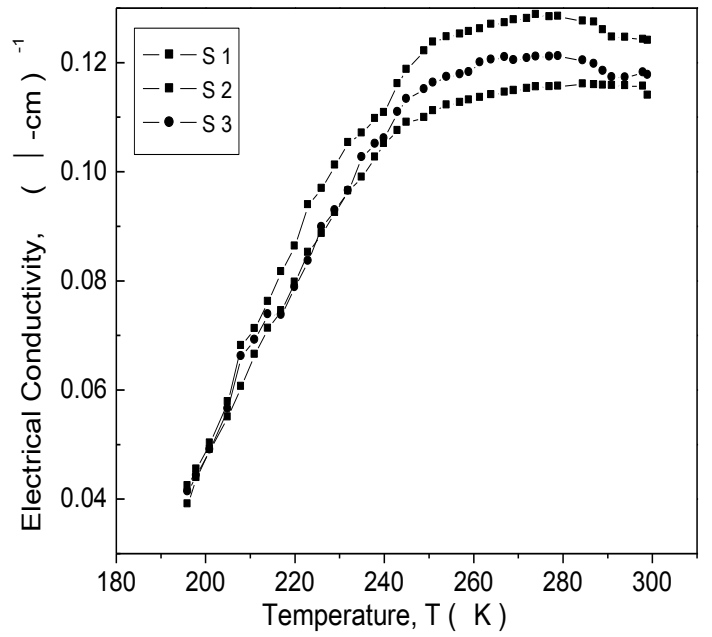

Fig. 2. Electrical conductivity ( ) versus temperature (T) of p-type silicon.

The curve in Fig. 3 shows linearity in the temperature range $(200-300 \mathrm{~K})$. From the slope of straight portion of the curve ionization energy of $\mathrm{B}$ acceptor in p-type $\mathrm{Si}$ samples were calculated as $0.047,0.049$ and $0.051 \mathrm{eV}^{1,2}$, respectively.

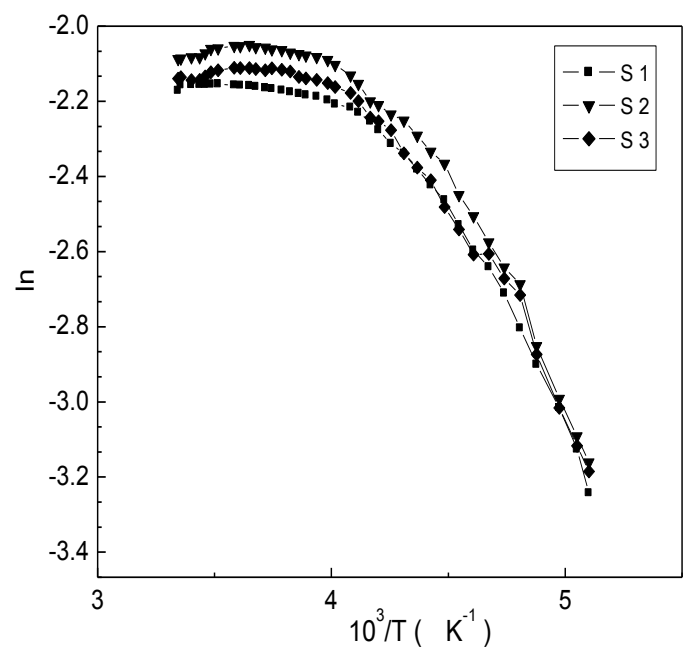

Fig. 3. In versus $1 / \mathrm{T}$ temperature curve of p-type silicon. 
Photoconductivity of a semiconducting crystal means the increase of electrical conductivity caused by the incident radiation on the crystal. The direct effect of illumination is to increase the density of charge carriers (electron-hole pairs) ${ }^{17}$.The change in conductance when sample being illuminated is given by the relation ${ }^{15}$.

$$
=\frac{V\left(R+r^{0}\right)}{r^{0} V R-V r^{0} R\left(R+r^{0}\right)}
$$

where $\mathrm{V}$ is the change in voltage when the sample is illuminated, $\mathrm{R}$ is the load resistance, $\mathrm{r}^{0}$ is the dark resistance of the sample and $\mathrm{V}$ is the supply voltage. When $\mathrm{R}=\mathrm{r}^{0}$ (Maximum sensitive regime), $\mathrm{V}$ attains the maximum value $\mathrm{V}_{\mathrm{m}}$ and photoconductivity ${ }_{\mathrm{pc}}^{*}$, can be expressed in terms of dark conductivity ${ }^{0}$ of the sample as ${ }^{15}$.

$$
{ }_{\mathrm{pc}}^{*}=4 \frac{\Delta \mathrm{V}_{\mathrm{m}}}{\mathrm{V}} \sigma^{0}
$$

Photoconductivity of the p-type Si samples was measured by varying the sample voltage, hence the sample current at a constant light intensity 2020 Lux at room temperature (300K). It was found in Fig.4 that photoconductivity remains almost constant with the increase of sample current $(0.1-0.8 \mathrm{~mA})$ and hence with the sample voltage $(4-14 \mathrm{~V})$.

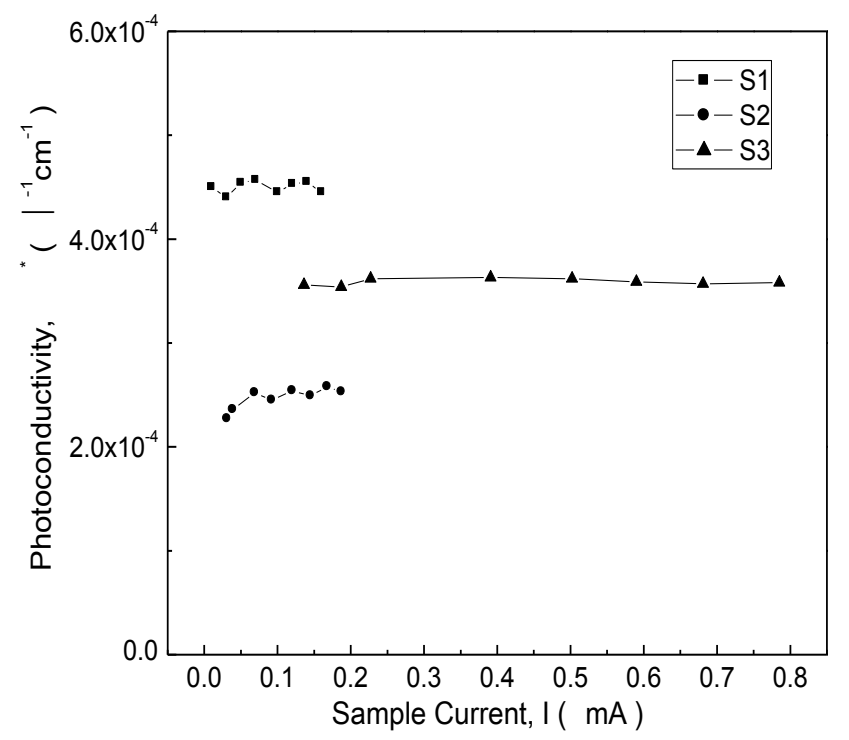

Fig. 4. Photoconductivity ( $\left.{ }^{*}\right)$ versus sample current (I) graph of p-type silicon at $300 \mathrm{~K}$.

Photoconductivity of the p-type Si was measured by varying light intensity in the range $37-2780$ Lux) at a constant sample voltage $(7 \mathrm{~V})$ and chopping frequency $45.60 \mathrm{~Hz}$ at room temperature $(300 \mathrm{~K})$. Non-linear increase of photoconductivity of p-type $\mathrm{Si}$ is found in Fig.5 with the increase of light intensity. This may be due to increase of the minority carriers due to the increase of light intensity 17,18

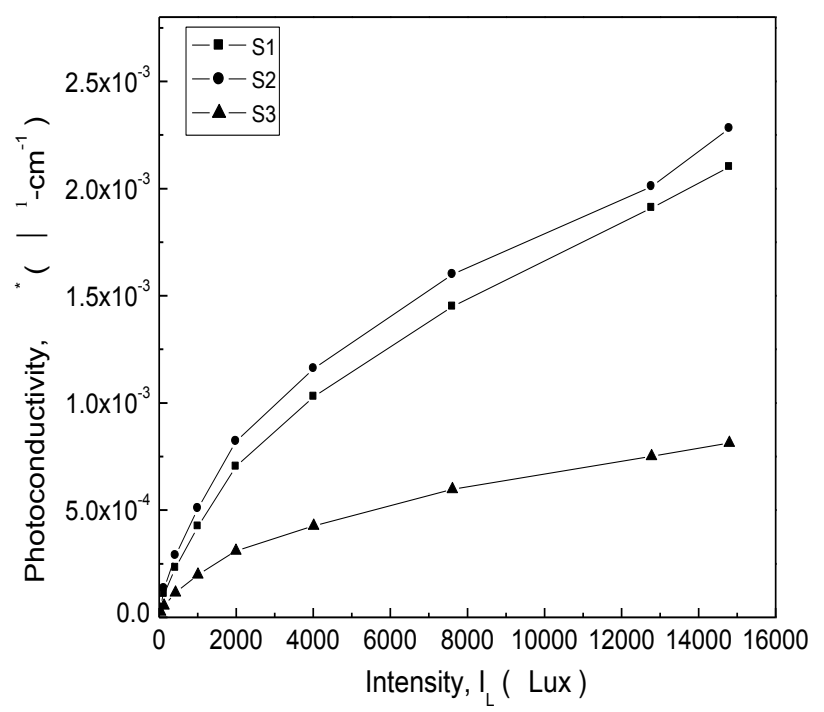

Fig. 5. Photoconductivity $\left({ }^{*}\right)$ versus light intensity $\left(\mathrm{I}_{\mathrm{L}}\right)$ graph of p-type silicon at $300 \mathrm{~K}$.

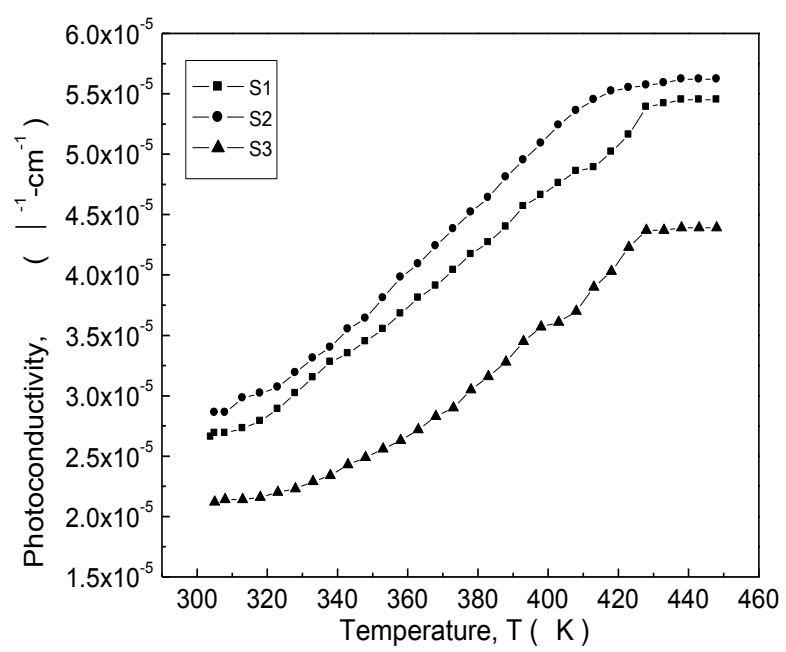

Fig. 6. Photoconductivity versus temperature graph of $p$ type silicon.

Temperature variation of photoconductivity of the p-type $\mathrm{Si}$ was also measured at constant sample voltage $(7 \mathrm{~V})$ and chopping frequency $45.60 \mathrm{~Hz}$ in the temperature range 308 $423 \mathrm{~K}$. It is observed from Fig.6 that photoconductivity increase was almost linear with temperature in the range 308 - $423 \mathrm{~K}$ which may be due to the generation of free carriers as a result of thermal excitation and it becomes constant after $423 \mathrm{~K}^{17-19}$.

Optical transmittance and reflectance of p-type $\mathrm{Si}$ was measured in the wavelength range $300-2500 \mathrm{~nm}$ at room temperature $(300 \mathrm{~K})$. Absorption co-efficient ( ) was calculated from the transmittance $(\mathrm{T})$ and reflectance $(\mathrm{R})$ data with the help of the following equation ${ }^{18}$,

$$
=\frac{1}{\mathrm{~d}}\left[1-\frac{\mathrm{T}\left(\mathrm{R}^{2}+1\right)}{(\mathrm{R}-1)^{2}+2 \mathrm{TR}^{2}}\right]
$$




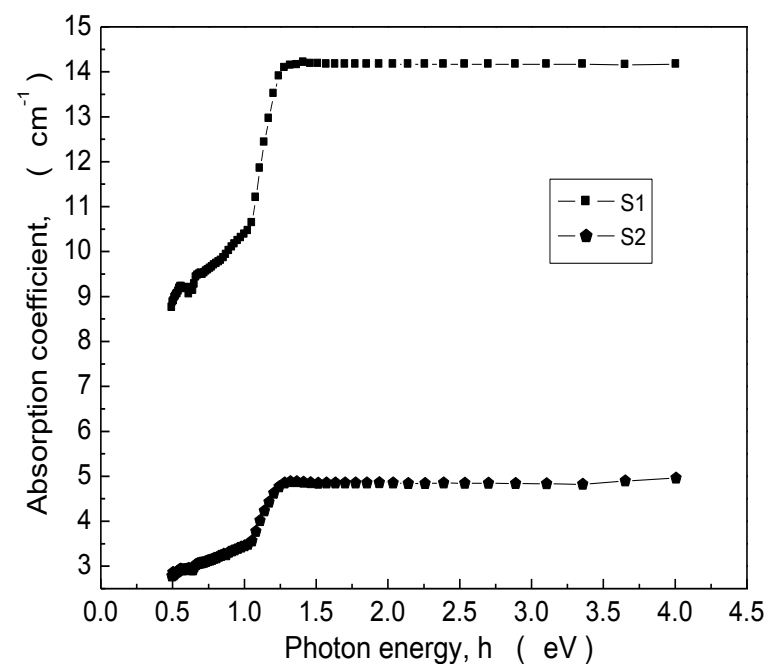

Fig. 7. Absorption co-efficients versus photon energy graph of p-type silicon.

Calculated values of absorption co-efficient ( ) of p-type Si were plotted against the photon wavelength as shown in Fig.7, there is no point at which the clear cut division can be seen between absorption due to direct and indirect processes.

Optical Energy gap (Eg) of materials is related to absorption co-efficient ( ),

$$
\mathrm{h}=\mathrm{A}\left(\mathrm{h}-\mathrm{E}_{\mathrm{g}}\right)^{\mathrm{n}}
$$

This is known as Tauc's relation ${ }^{20}$. Where A is Tauc's parameter, $\mathrm{h}$ the photon energy, $\mathrm{E}_{\mathrm{g}}$ is the band gap and $\mathrm{n}$ is an index which is taken $\mathrm{n}=1 / 2$ for an allowed direct transition and $\mathrm{n}=2$ for indirect transition.

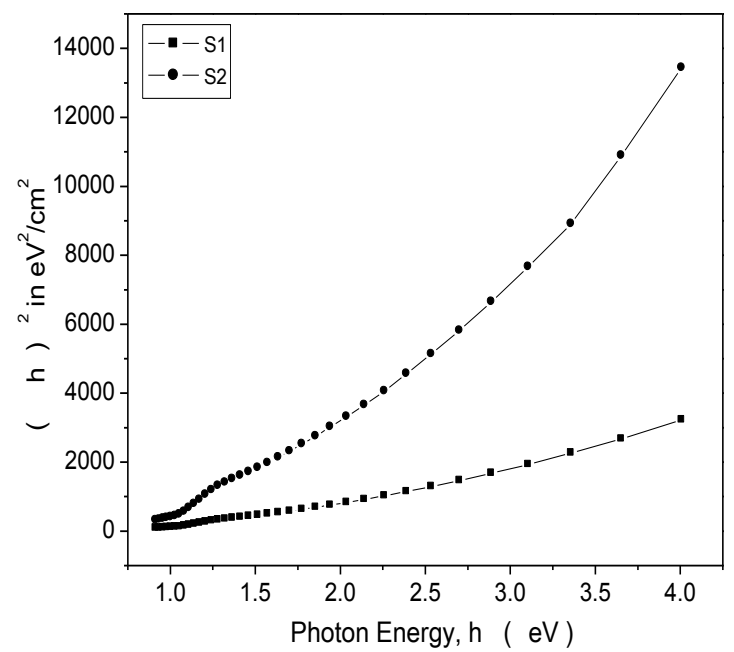

Fig. 8. ( $\mathrm{h})^{2}$ vs. photon energy (h ) graph of p-type

Fig. 8 shows the plot of $(\mathrm{h} \quad)^{2}$ with photon energy $(\mathrm{h} \quad)$ in the wavelength range $300-2500 \mathrm{~nm}$ at room temperature 300 $\mathrm{K}$. The extrapolation of the straight line in the higher energy region gives the value of direct band gap of the p-type $\mathrm{Si}$, which was found to be 2.2 and $2.1 \mathrm{eV}^{4,7,10}$, respectively.
There is another transition region found in the lower energy region which appears due to indirect transition.

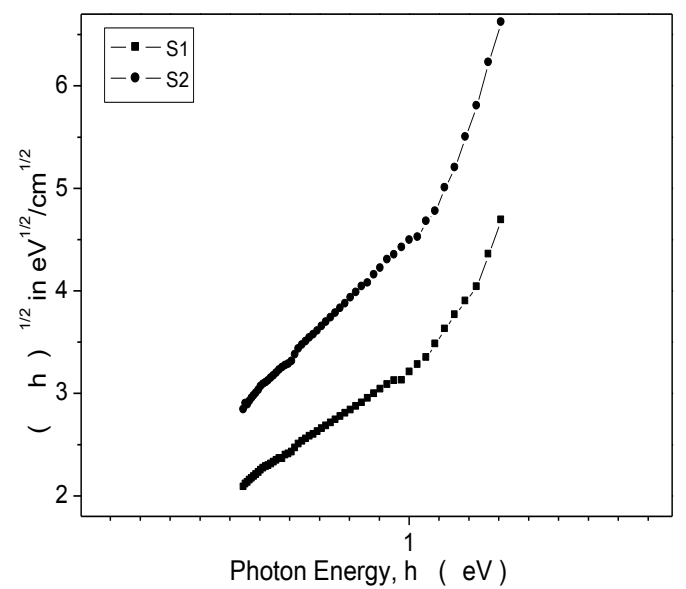

Fig. 9. ( $\mathrm{h})^{1 / 2}$ vs. photon energy (h ) of p-type silicon.

The indirect band gap of p-type $\mathrm{Si}$ was found from the extrapolation of the straight line part of the graph (Fig.9) in the lower energy region. The values were between 0.95 and $1.0 \mathrm{eV}^{4,10}$, respectively.

The X-ray diffraction (XRD) pattern of p-type $\mathrm{Si}$ is shown

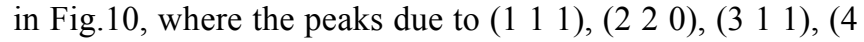

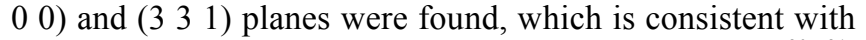
the XRD pattern of diamond cubic lattice structure ${ }^{20,21}$. Lattice parameter is calculated to be $5.419 \AA$ from the XRD data which was near the standard value ${ }^{22}$. Some impurity peaks were found in the diffraction pattern, which may be due to $\mathrm{p}$-type doping.

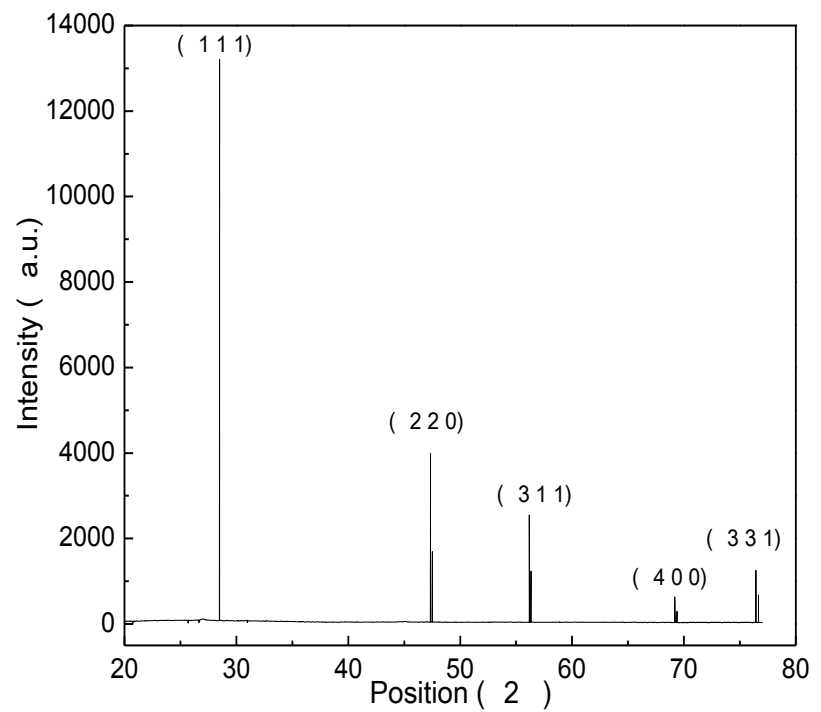

Fig. 10. The X-ray diffraction pattern of p-type silicon.

\section{Conclusions}

Electrical conductivity of p-type Si shows an increase with temperature in the range $190-300 \mathrm{~K}$ and the acceptor ionization energy $\left(\mathrm{E}_{\mathrm{A}}\right)$ obtained was between 0.047 $0.051 \mathrm{eV}$. Photoconductivity measurement shows that sample current has almost no effect on photoconductivity in 
the range $(0.1-0.8 \mathrm{~mA})$. Photoconductivity is found to be increasing nonlinearly with the increase of light intensity and linearly with the increase of temperature. It can be said that p-type Si shows nice photoconductive response to both light intensity and temperature. Direct band gap of p-type Si is found to be 2.2 and $2.1 \mathrm{eV}$ and indirect band gap is found to be 0.95 and $1.0 \mathrm{eV}$. The X-ray diffraction (XRD) pattern of p-type $\mathrm{Si}$ was consistent with the XRD pattern of diamond cubic type of crystal structure and Lattice parameter is calculated to be $5.419 \AA$. It may be concluded that the material shows good electrical and optical properties and it may be quite suitable in fabrication of electronic and photoconductive devices.

\section{Acknowledgements}

Authors are thankful to Experimental Physics Division, Atomic Energy Centre, Dhaka, for providing necessary experimental facilities.

\section{References}

1. Morin, FJ and J.P. Maita, 1954. Electrical properties of Silicon containing Arsenic and Boron. Phys. Review 96(1), 28-35.

2. Walter, S and C.E. Jones, 1979. Infrared spectra of new acceptor levels in boron -doped and gallium-doped silicon. $J$. Appl. Physics 50, 7258.

3. Senawiratne, J, J.S. Cites, J.G. Couillard, J. Moll, C.A.K Patrick and G. Whiting, 2009. Boron and Phosphorus Implantation Induced Electrically Active Defects in p-Type Silicon. Solid State Phenomena 156-158,313-317.

4. Dash, WC and R. Newman, 1955. Intrinsic optical absorption in single-crystal Germanium and Silicon at $77^{\circ} \mathrm{K}$ and $300^{\circ} \mathrm{K}$. Phys. Review 99(4), 1151-1155.

5. Väinölä, H, E. Saarnilehto, M. Yli, Koski, A. Haarahiltunen, J. Sinkkonen, G. Berenyi, T. Pavelka, 2005. Quantitative copper measurement in oxidized p-type silicon wafers using microwave photoconductivity decay. Appl. Phys. Letter 87, 032109.

6. Bakr, NA, A. M. Funde, V.S. Waman, M.M. Kamble, R.R. Hawaldar, D.P. Amalnerkar, S. W. Gosavi and S.R. Jadkar, 2011. Determination of the optical parameters of a Si:H thin films deposited by hot wire chemical vapour deposition technique using transmission spectrum only. Pramana J. physics 76 ( 3), 519-531.

7. Esmaeili-Rad, MR, A. Sazonov, A.G. Kazanskii, A.A. Khomich and A. Nathan, 2007. Optical properties of nanocrystalline silicon deposited by PECVD. J. Mat. Science 18(1), 405-409.
8. Kim, J, A. Babajanyan, T. Sargsyan, H. Melikyan, S. Kim, B. Friedman and K. Lee, 2009. Investigation of photoconductivity of silicon solar cells by a near-field scanning microwave microscope. Proceedings of the 10th International Scanning Probe Microscopy Conference 109(8), 958-962.

9. Green, MA and M.J. Keevers, 1995. Optical properties of intrinsic silicon at $300 \mathrm{~K}$. Progress in Photovoltaics: Research and Applications 3 (3), 189 - 192 (1995)

10. Adhikary, K and S. Ray, 2007. Characteristics of p-type nanocrystalline silicon thin films developed for window layer of solar cells. J. Non-Cryst. Solids 353(22-23), 2289-2294.

11. Sharmin, M, S. Choudhury, N. Akhtar, T. Begum, 2012. Optical and transport properties of p-type GaAs. J. Bangladesh Academy of Sciences 36 (1), 97-107.

12. Das, C, J. Begum, T. Begum, S. Choudhury, 2013.Effect of thickness on the optical properties of GaAs thin films. $J$. Bangladesh Academy of Sciences 37 (1), 83-91.

13. Knol, M, 1959. Material and Processes in Electron devices, Berlin.

14. Van Der Paw, LJ, 1958. A Method of Measuring Specific Resistivity and Hall Effect of Disk or Arbitrary Shape. Philips Res. Rep.

15. Ryvkin, SM, 1964. Photoelectric Effect in Semiconductors. Consultant Bureau: New York.

16. Kittel, C, 1996. Introduction to Solid State Physics. John Willey \& (ASIA) Pte. Ltd.

17. Moss, TS, 1959. Optical Properties of Semiconductors. New York.

18. Schroder, DK, 1998. Semiconductor Material and Device Characterization. John Wiley: Inc. New York.

19. Müller, DC, 2004. Deactivation and Activation of Donors in Silicon. Dissertation, Swiss Federal Institute of Technology, Zurich.

20. Joshi GP, R. Mangal, N.S. Saxena, T.P. Sharma, 2002. Band Gaps of Nanocomposites. Ind. J. Pure \& Appl. Physics 40(4), 297-300.

21. Bubáková, R, J. Drahokoupil and A. Fingerland, 1962.The single crystal diffraction patterns of silicon, Cechoslovackij fiziceskij zurnal B 12(10), 764-775.

22. Odo, EA, D. T. Britton, G. G. Gonfa and M. Harting, 2012. Structure and Characterization of Silicon Nanoparticles Produced Using a Vibratory Disc Mill. The African Review of Physics 7, 45-56.

23. Hubbard, CR, H. E. Swanson and F. A. Mauer, 1975. A silicon powder diffraction standard reference material. $J$. Appl. Cryst.8, 45-48. 